\title{
Population genetic structure in European lobsters: implications for connectivity, diversity and hatchery stocking
}

\author{
Charlie D. Ellis ${ }^{1,2, *}$, David J. Hodgson ${ }^{3}$, Carly L. Daniels ${ }^{2}$, Michael Collins ${ }^{3}$, \\ Amber G. F. Griffiths ${ }^{1,4}$ \\ ${ }^{1}$ Environment and Sustainability Institute, University of Exeter, Penryn Campus, Penryn, Cornwall TR10 9FE, UK \\ ${ }^{2}$ National Lobster Hatchery, South Quay, Padstow, Cornwall PL28 8BL, UK \\ ${ }^{3}$ Centre for Ecology and Conservation, University of Exeter, Penryn Campus, Penryn, Cornwall TR10 9FE, UK \\ ${ }^{4}$ Present address: FoAM Kernow, Studio E, Jubilee Warehouse, Commercial Road, Penryn, Cornwall TR10 8AE, UK
}

\begin{abstract}
The European lobster Homarus gammarus is a marine crustacean prized for seafood, but populations across its range are threatened by fishery overexploitation. The species' larval stages are planktonic, suggesting considerable dispersal among populations. The potential threats of overexploitation and erosion of population structure due to hatchery releases or inadvertent introductions make it important to understand the genetic structuring of populations across multiple geographic scales. Here we assess lobster population structure at a fine scale in Cornwall, southwestern UK, where a hatchery-stocking operation introduces cultured individuals into the wild stock, and at a broader European level, in order to compare the spatial scale of hatchery releases with that of population connectivity. Microsatellite genotypes of 24 individuals from each of 13 locations in Cornwall showed no fine-scale population structure across distances of up to $\sim 230 \mathrm{~km}$. Significant differentiation and isolation by distance were detected at a broader scale, using 300 additional individuals comprising a further 15 European samples. Signals of genetic heterogeneity were evident between an Atlantic cluster and samples from Sweden. Connectivity within the Atlantic and Swedish clusters was high, although evidence for isolation by distance and a transitional zone within the eastern North Sea suggested that direct gene exchange between these stocks is limited and fits a stepping-stone model. We conclude that hatchery-reared lobsters should not be released where broodstock are distantly sourced but, using Cornwall as a case study, microsatellites revealed no evidence that the normal release of hatchery stock exceeds the geographic scale of natural connectivity.
\end{abstract}

KEY WORDS: Stock enhancement · Population connectivity · Fisheries management · Isolation by distance $\cdot$ Conservation

\section{INTRODUCTION}

It was once commonly assumed that extensive dispersal capabilities of larval or adult life-stages would effectively maintain genetic panmixis among widely distributed marine species (Hellberg 2009). However, scrutiny of marine crustacean populations at the molecular level shows that, although some spe-

${ }^{*}$ Corresponding author:

charlie.ellis@nationallobsterhatchery.co.uk

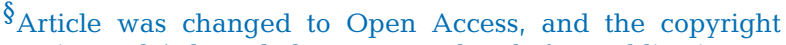
notice and Acknowledgements updated after publication.

This corrected version: January 25, 2017 cies appear to be panmictic (e.g. Norway lobster Nephrops norwegicus, Pampoulie et al. 2011; snow crab Chionoecetes opilio, Albrecht et al. 2014), others exhibit extensive subpopulation divergence, even at modest spatial scales (e.g. ghost shrimp Callichirus islagrande, Bilodeau et al. 2005; European spiny lobster Palinurus elephas, Babbucci et al. 2010; northern shrimp Pandalus borealis, Jorde et al. 2015). Spatial

(C) The authors 2017. Open Access under Creative Commons by Attribution Licence. Use, distribution and reproduction are unrestricted. Authors and original publication must be credited.

Publisher: Inter-Research · www.int-res.com 
genetic heterogeneity suggests limits to intraspecific connectivity, information that is vital for the sustainable management of populations pressured by fishing (Waples et al. 2008, Reiss et al. 2009). Where the spatial boundaries of biological populations are unknown or mismatched to those of management units, conservation initiatives may fail to protect discrete stocks, making fisheries vulnerable to localised depletion or collapse (Kenchington et al. 2003, Waples et al. 2008, Reiss et al. 2009).

The European lobster Homarus gammarus L. is a decapod crustacean inhabiting the coastal shelf seas of the eastern North Atlantic and has been the subject of hatchery stocking in recent decades (Ellis et al. 2015a). The lobster ranges from Arctic Norway to Morocco, including the semi-enclosed seas of the Mediterranean and the Kattegat, bounded by the Black Sea and Baltic Sea, respectively (Jørstad et al. 2004, Triantafyllidis et al. 2005). The species' market value makes it highly prized by trap fishers, so stocks are of great importance to inshore ecosystems and the traditional fishing communities that they support (Ellis et al. 2015a). However, overexploitation during the 20th century led to severe stock depletions across regions including Scandinavia and the Mediterranean, from which recovery has since been slow or absent (Ellis et al. 2015a). This has encouraged the rearing of $H$. gammarus larvae in aquaria-based hatcheries to produce juvenile lobsters for release to supplement productive fisheries and restore yields in heavily depleted areas (Addison \& Bannister 1994).

A key risk of stocking compared to alternative fisheries conservation strategies (i.e. areas closed to fishing; Hoskin et al. 2011, Moland et al. 2013) is that the admixture of hatchery stock can compromise the fitness of wild populations: rearing in artificial environments can promote traits that are maladapted to the wild and may be introduced to natural stock (Araki et al. 2007, Christie et al. 2012a), while relative genetic homogeneity among cultured individuals may reduce the effective size of the targeted stock (Christie et al. 2012b). Hatchery stocking also has the potential to disrupt the structuring of intra-specific genetic diversity (Ward 2006, Lorenzen et al. 2010).

Lobster hatcheries typically source ovigerous broodstock from the wild, across the spatial ranges covered by local fishers. Larvae from these females are reared, and then later released, in communal cohorts based on the date of hatch (Ellis et al. 2015a). This risks the introduction of individuals beyond the natural spatial range of their subpopulations. Such introductions can erode the genetic structure of populations, reducing diversity in the wild gene pool and inhibiting the evolutionary adaptability of stocks, compromising their conservation (Kenchington et al. 2003, Ward 2006), as noted among some marine and anadromous fish (Ayllon et al. 2006, Blanco Gonzalez et al. 2015). Knowledge of population structure is therefore vital to ensure that released stock is genetically compatible with natural stock (Ward 2006) and that unintended genetic impacts of hatchery stocking on the admixed population can be monitored (Koskinen et al. 2002).

Basic assessments of regional genetic diversity have accompanied H. gammarus stocking in Kvitsøy, Norway (Agnalt et al. 1999, Jørstad \& Farestveit 1999) and Helgoland, Germany (Ulrich et al. 2001, Schmalenbach et al. 2011). However, the methods used-allozymes and randomly amplified polymorphic DNA analysis, respectively - have been largely superseded and often failed to detect subtle genetic structure in other species (e.g. Burton 1994, Lougheed et al. 2000). Elsewhere, lobster stocking has occurred without any knowledge of fine-scale spatial structure and the impact of hatchery releases on wild lobster population genetics remains empirically unassessed (Ellis et al. 2015a). Lorenzen et al. (2010) advocate local adaptation to be assumed to exist at scales of $10 \mathrm{~s}$ of $\mathrm{km}$ where population structure is unassessed, but historic and current lobster stocking ventures have frequently sourced broodstock and released juveniles more widely.

Several discrete $H$. gammarus subpopulations have been proposed in recent years via evidence of genetic or oceanographic isolation (Triantafyllidis et al. 2005, Øresland \& Ulmestrand 2013), or trait variation (Ellis et al. 2015b), with extensive differentiation apparent between stocks as close as $142 \mathrm{~km}$ apart (Jørstad et al. 2004). We aimed to investigate the fine-scale genetic structure of a lobster population around the Atlantic peninsula of Cornwall in the southwestern UK, where a regional stock enhancement programme collects ovigerous females to rear mixed batches of juveniles for wild release throughout a $\sim 250 \mathrm{~km}$ section of coastal waters (Ellis et al. 2015a). This programme aims to increase production and release numbers to ecologically important levels, but is concerned that the supplementation of fragile stocks should not affect population genetic structuring. To evaluate whether current stocking strategies may unintentionally erode local genetic structure, we used 14 microsatellite loci to estimate the gene flow among lobsters from 13 geographic samples throughout Cornwall and nearby offshore islands. We further assessed the genetic characteristics of an additional 15 geographic samples collected throughout Europe. 


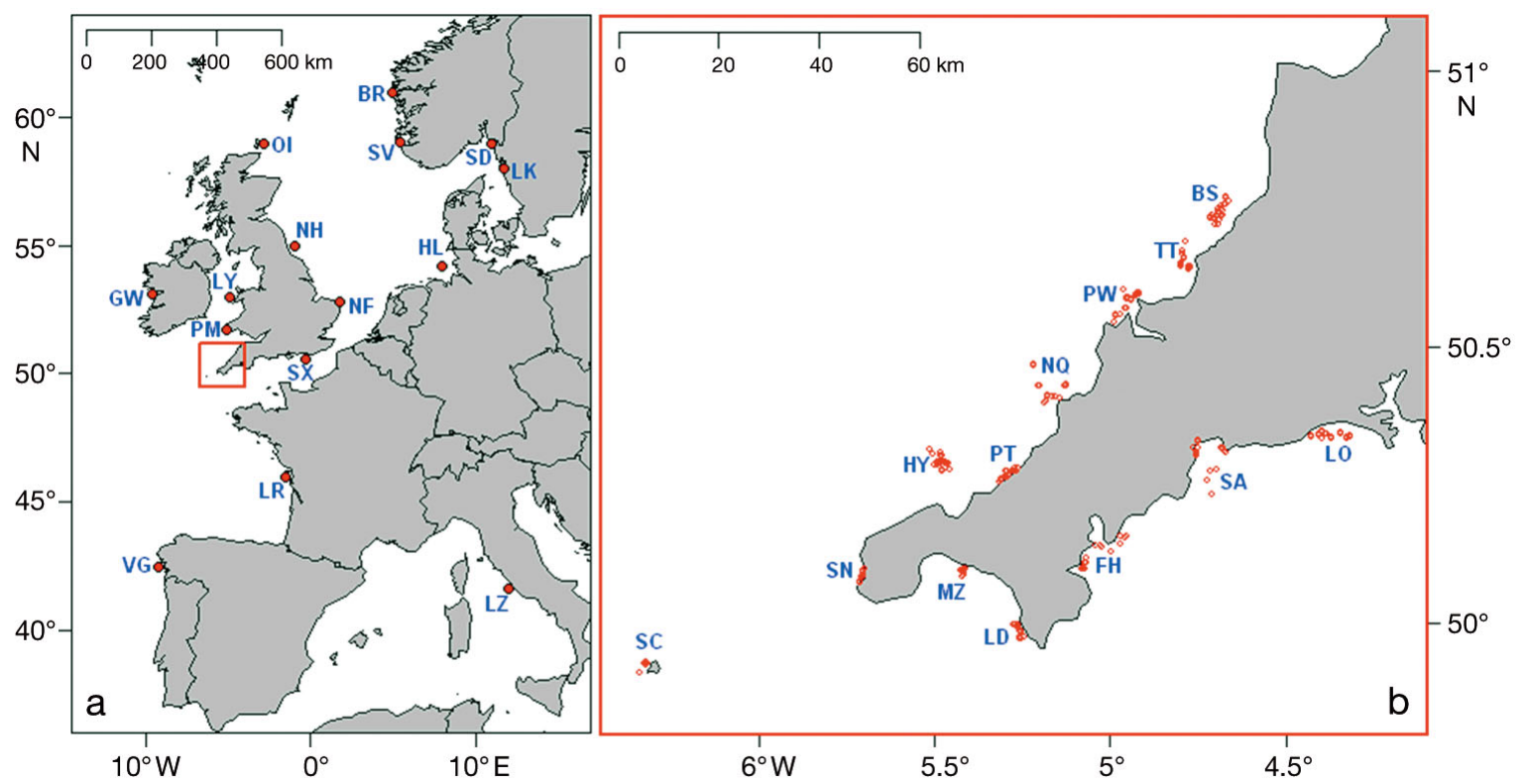

Fig. 1. (a) Sampling locations around Europe. (b) Inset red area in (a), showing locations of fine-scale sampling around Cornwall, UK. For lettered keys and sample information, see Table 1

\section{MATERIALS AND METHODS}

\section{Sample collection and microsatellite genotyping}

Samples from around mainland Cornwall, UK (Fig. 1, Table 1), were obtained during 2013, collected in situ aboard commercial potting vessels to ensure confidence in fine-scale location data. A tissue sample (pleopod clip) and a log on the custombuilt sampling app DORIS (Teacher et al. 2013) was taken for each lobster (including pre-recruits). DORIS recorded each lobster's capture location via GPS and logged a photograph to determine sex and carapace length (mm). Extracted DNA (Norwegian samples), genotype data (Swedish samples) or fresh tissue samples (all other samples) from lobsters comprising the 15 broader scale samples (Fig. 1, Table 1) were provided with only approximate region and date of capture and, apart from the Isles of Scilly area, no size or sex information. The total number of lobsters was 612, including 312 individuals sampled at fine spatial scale around Cornwall, 108 individuals sampled by collaborators at a broader scale around Europe, and pre-published data for 192 individuals sampled from western Sweden (Huserbråten et al. 2013).

Protocols for DNA extraction, primer synthesis, multiplexed PCR amplification of loci, fragment analysis and allele sizing followed those outlined in Ellis et al. (2015c). Individuals were each screened at 15 microsatellites - 12 from André \& Knutsen (2010)
Table 1. Map key for Fig. 1 and approximate location of geographic lobster samples, with the number of individuals genotyped (n). All samples collected 2013, except ${ }^{*}$ (2000) and $^{* *}(2010)$

\begin{tabular}{|llr|}
\hline Map key & Geographical sample & $\mathrm{n}$ \\
\hline BS & Boscastle, UK & 24 \\
TT & Tintagel, UK & 24 \\
PW & Padstow, UK & 24 \\
NQ & Newquay, UK & 24 \\
PT & Portreath, UK & 24 \\
HY & Hayle, UK & 24 \\
SN & Sennen, UK & 24 \\
MZ & Marazion, UK & 24 \\
LD & Lizard, UK & 24 \\
FH & Falmouth, UK & 24 \\
SA & St. Austell, UK & 24 \\
LO & Looe, UK & 24 \\
SC & Scilly Isles, UK & 24 \\
BR & Bergen, Norway & 8 \\
SV & Stavanger, Norway ${ }^{*}$ & 8 \\
SD & Strömstad, Sweden ${ }^{* *}$ & 96 \\
LK & Lysekil, Sweden ${ }^{*}$ & 96 \\
HL & Helgoland, Germany & 5 \\
OI & Orkney, UK & 10 \\
NH & Northumberland, UK & 11 \\
NF & Norfolk, UK & 8 \\
SX & Sussex, UK & 9 \\
LY & Llyn, UK & 10 \\
PM & Pembrokeshire, UK & 10 \\
GW & Galway, Ireland & 7 \\
LR & La Rochelle, France & 7 \\
VG & Vigo, Spain & 8 \\
LZ & Lazio, Italy & 7 \\
Total & & 612 \\
\hline
\end{tabular}


and 3 from Ellis et al. (2015c) - except 88 of the 96 individuals from both Lysekil ('Gullmarfjord' in Huserbråten et al. 2013) and Strömstad ('Singlefjord' in Huserbråten et al. 2013), for which genotype data were supplied for only the 12 loci of André \& Knutsen (2010). Ambiguous or non-amplifying loci were retested in single-locus PCR and fragment analysis procedures. To estimate genotyping error, $\mathrm{PCR}$, fragment analysis and allele scoring were independently repeated for a sub-sample of individuals ( $\mathrm{n}=43 ; 7 \%$ of the total samples). The data provided from Huserbråten et al. (2013) were calibrated by genotyping and analysing a sub-sample of 8 individuals from each of the 2 Swedish samples, with allele scores of remaining individuals being adjusted in accordance with the genotyped samples where necessary.

\section{Statistical analysis}

The web-based GENEPOP 4.2 software (Raymond \& Rousset 1995) was used to calculate allele frequencies, to carry out log-likelihood tests of linkage disequilibrium, among loci globally and within each sample, and to check for deviations from HardyWeinberg equilibrium (HWE), at each locus and within geographic samples, using exact probability tests of heterozygote deficiency. FreeNA (Chapuis \& Estoup 2007) was used to check the likelihood of null alleles being present, while LOSITAN (Antao et al. 2008) was used to detect loci under selection. To measure basic genetic diversity, per-sample allelic richness $\left(A_{R}\right)$ was calculated using FSTAT 2.9.3.2 (Goudet 2001), while the observed $\left(H_{\mathrm{O}}\right)$ and expected $\left(H_{\mathrm{E}}\right)$ heterozygosity were calculated in ARLEQUIN 3.5 (Excoffier \& Lischer 2010), both per-locus and per-sample.

FSTAT was used to calculate global and pairwise measures of the fixation index $F_{\mathrm{ST}}\left(\theta_{i}\right.$ Weir \& Cockerham 1984), with standard error and confidence intervals obtained by jackknifing and bootstrapping over loci, and global and pairwise p-values permuted by $G$-tests $\left(P_{\mathrm{G}}\right)$. To allow direct comparisons with power analysis results, p-values were also estimated by Fisher's $\left(P_{\text {Fish }}\right)$ exact test in GENEPOP. An adjusted significance threshold for pairwise $F_{\mathrm{ST}}$ p-values was calculated using the modified false discovery rate (FDR; Benjamini \& Yekutieli 2001). FSTAT was used to provide per-locus measures of $F_{\mathrm{ST}}$ and standard error, with p-values $\left(P_{\text {Fish }}\right)$ calculated in GENEPOP. The R (R Core Team 2012) package DEMEtics (Gerlach et al. 2010) was used to estimate global and per-locus actual differentiation $D$ (Jost 2008), a more consistent measure than $F_{\mathrm{ST}}$ with some multi-allelic, multi-locus genotyping (Jost 2009). DEMEtics provided bootstrapped confidence intervals and $p$-values $\left(P_{\mathrm{G}}\right)$. Minimum Euclidean oceanic distances between geographic samples were regressed against pairwise $F_{\text {ST }}$ in a 10000 permutation Mantel test of isolation by distance (IBD) in GENEPOP. The effective population size $\left(N_{\mathrm{e}}\right)$ of each geographic sample was estimated using NeEstimator 2.01 (Do et al. 2014).

The Bayesian software STRUCTURE 2.3.4 (Pritchard et al. 2000) was used to infer population clusters. Model runs had a burn-in of 400000 followed by 800000 Markov chain Monte Carlo (MCMC) steps, for 2 to 10 assumed clusters $(K)$ each simulated for 5 iterations, and allele frequencies correlated. Population admixture and a priori location (LOCPRIOR) settings were enabled, to improve the detection of weak structuring in open populations (Hubisz et al. 2009). Separate STRUCTURE runs were implemented without population admixture or LOCPRIOR settings, and without acquired Swedish genotype data to test the effect these had on the optimisation of $K$. Loci were also tested individually with a burn-in of 200000 and 400000 MCMC steps, for 3 iterations of $K=2$. Any locus showing evidence for population structure in one of these iterations was additionally run for a total of 5 iterations per cluster assuming $K=2$ to 10 . STRUCTURE outputs were post-processed in the web versions of STRUCTURE HARVESTER (Earl \& von Holdt 2012), which estimated the optimal number of $K$ using Evanno's delta- $K$ method (Evanno et al. 2005), and CLUMPAK (Kopelman et al. 2015), which formed a convergence between iterations for each value of $K$. ARLEQUIN was used to perform an analysis of molecular variance (AMOVA), to proportionally attribute the observed genetic variation to individuals, samples and cluster groupings (as inferred by STRUCTURE).

\section{Analysis of power}

It is important to assess the power of genetic data when using molecular markers to infer the spatial structuring of populations (Putman \& Carbone 2014). The suitability of various sample sizes to depict genetic diversity accurately was evaluated via the total number of alleles detected (across all loci) per sample size. To assess this, the mean allelic diversity detected by the 2 largest samples, those from Lysekil and Strömstad in Sweden (each $\mathrm{n}=96$ ), was calculated when reducing the sample sizes by intervals of 8 individuals (removed at random). 
POWSIM 4.1 (Ryman \& Palm 2006) was used to estimate the probability $\left(P_{\text {Fish }}\right)$ of Type I $(\alpha)$ error (a rejection of the null hypothesis of genetic homogeneity when it is true) and the power of the loci to detect heterogeneity according to the sampling design used. POWSIM estimates $\alpha$ error rate and power as the proportion of random sub-samples that show statistically significant $(p<0.05)$ genetic differentiation after a base population, simulated from observed allele frequencies, undergoes genetic drift for a specified number of generations. The power deficit is the probability of Type II ( $\beta$ ) error (a failure to reject the null hypothesis of genetic homogeneity when it is false). Separate simulations were conducted for the detection of overall and pairwise differentiation, both for broad- and fine-scale base populations, using $N_{\mathrm{e}}$ estimates of 2000 and 10000 to compare the generations of drift required to attain an expected $F_{\mathrm{ST}}$. The number and sizes of sub-samples used to measure differentiation following drift matched those of our broad- and fine-scale datasets, with an additional scenario of only 8 individuals per location (the mean size outside Sweden and Cornwall) assessed to evaluate potential limitations of broad-scale sampling.

See Supplement 1 at www.int-res.com/articles/suppl/ m563p123_supp.pdf for additional details of methodologies.

\section{RESULTS}

\section{Loci screening and viability}

The maximum genotyping error rate was estimated to be $1.8 \%$, with 22 of 1194 allele scores differing between the original screening and independent repeats. The locus HGA8 was found to be significantly deficient in heterozygotes, both globally ( $p<0.001$ ) and within the majority of geographic samples. This was the result of the failure of one or more alleles to amplify; null alleles at HGA8 were estimated to have a global frequency of 0.08 , a maximum frequency of 0.2 among geographic samples, and were confirmed via a separate parentage analysis (Ellis et al. 2015c). As a result, data for this locus were removed from the dataset ahead of analysis. A much rarer null allele at a second locus, HGC129, was detected via parentage (Ellis et al. 2015c) but had an estimated global frequency of only 0.03. Genotype data at this locus were retained, since non-amplifying alleles of such low frequency generally have a negligible influence on population genetic analysis (Falush et al. 2007).
After the removal of HGA8, no loci significantly deviated from HWE (see Table S1 in Supplement 2 at www.int-res.com/articles/suppl/m563p123_supp.pdf). One pair of markers (HGD111 and HGD129) showed evidence of linkage, but these were retained, as linkage disequilibrium was detected $(p<0.05)$ in only 2 of the 28 regional samples. A total of 3 markers were designated as being potentially influenced by directional or balancing selection: HGC103 exhibited a higher $F_{\mathrm{ST}}$ than was expected via $H_{\mathrm{E}}$ (directional), and HGC131b and HGC120 both exhibited a lower $F_{\mathrm{ST}}$ than was expected via $H_{\mathrm{E}}$ (balancing). These results were all marginal under evolutionary models assuming either infinite alleles (Fig. S1 in Supplement 2) or stepwise mutation, so the potential candidate loci were retained.

\section{Genetic diversity}

Among geographic samples, only the sample from Tintagel, UK, was found to deviate from HWE ( $\mathrm{p}=$ 0.03; Table S2), although this stemmed from only 3 of 14 loci falling significantly outside HWE $(\mathrm{p}<0.05)$. Overall, there was no disequilibrium from HWE expectations across all loci and all populations ( $\mathrm{p}=$ 0.998). Among samples, $H_{\mathrm{O}}$ ranged from 0.598 to $0.723, H_{\mathrm{E}}$ from 0.637 to 0.710 , and the global $H_{\mathrm{E}}$ exceeded $H_{\mathrm{O}}$ by only 0.004 . Average $A_{\mathrm{R}}$ was lowest for the sample from La Rochelle, France (3.20), and highest for Lysekil, Sweden (3.88), with a weighted global mean of $3.67 \pm 0.14$ (mean $\pm \mathrm{SD}$ ). The estimated effective population size, $N_{\mathrm{e}}$, from which samples were derived ranged from 22.0 (Northumberland, UK) to infinity (14 samples). Many of the lower values for $N_{\mathrm{e}}$ were among fine-scale samples in Cornwall; when pooling these samples together, $N_{\mathrm{e}}$ in Cornwall was infinite, and 13 of the 16 estimates of sample $N_{\mathrm{e}}$ were $>2000$.

\section{Genetic differentiation and structure}

At a broad European scale, overall $F_{\mathrm{ST}}$ was 0.007 $\left(P_{\mathrm{G}}=0.001 ; 95 \% \mathrm{CI}=0.002\right.$ to $\left.0.012 ; P_{\text {Fish }}=0.000\right)$ and $D$ was $0.011\left(P_{\mathrm{G}}=0.013 ; 95 \% ; \mathrm{CI}=0.000\right.$ to 0.023) (Table S1). Pairwise $F_{\mathrm{ST}}$ across all samples ranged from -0.016 to 0.048 (Table 2), with 50 of 378 pairwise comparisons being $\mathrm{p}<0.05$ when permuted by $G$, and 105 of 378 via Fisher's exact test. Control of the FDR adjusted the level of statistical significance with $95 \%$ confidence to $\alpha=0.0077$, which was attained by 11 sample comparisons by $P_{\mathrm{G}}$, and 50 via 


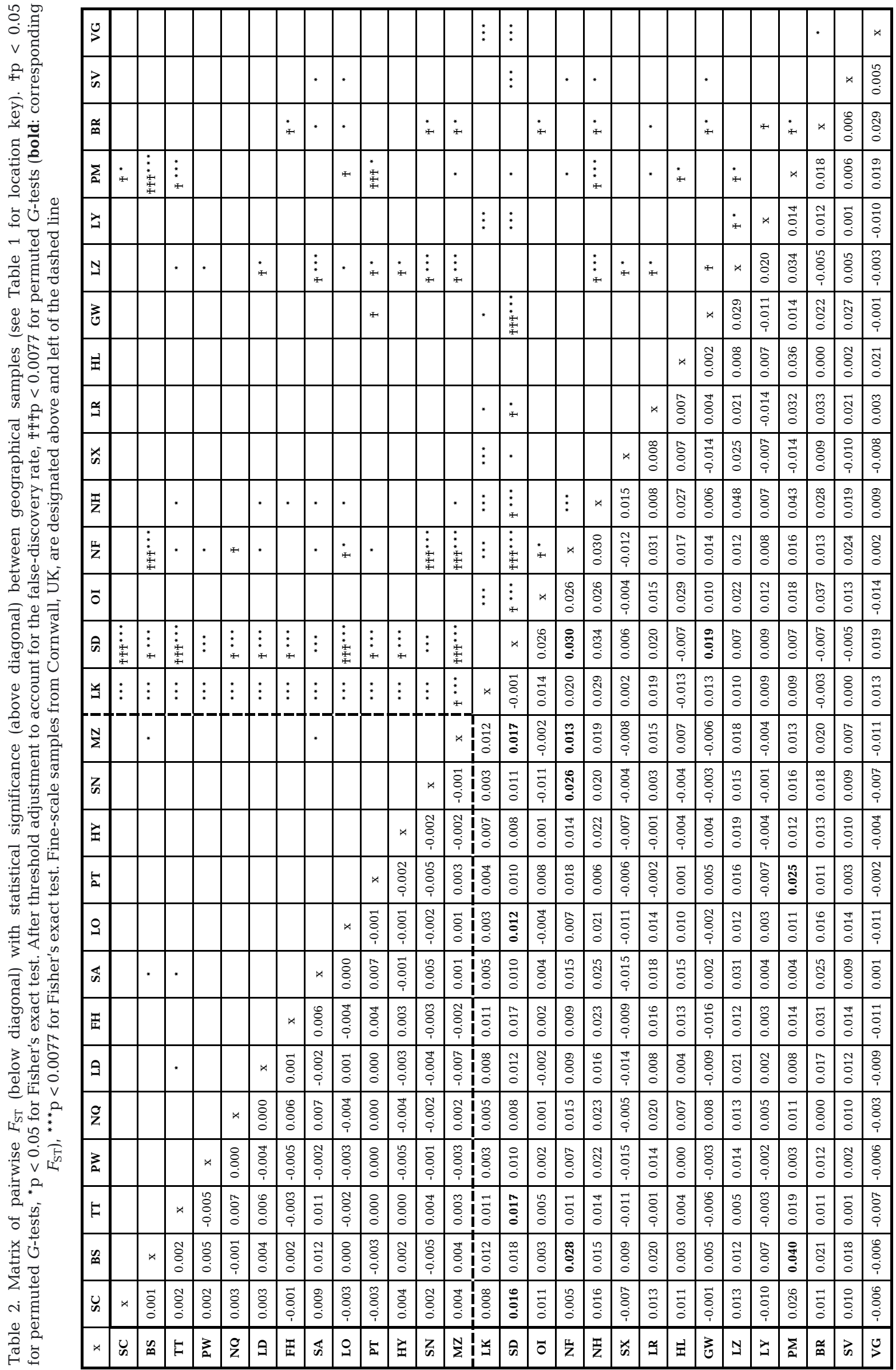


$P_{\text {Fish }}$. The samples most frequently featuring in significant comparisons were Strömstad ( 6 by $P_{\mathrm{G}}, 20$ by $P_{\text {Fish }}$ ), Lykesil (0 by $P_{\mathrm{G}}, 19$ by $P_{\text {Fish }}$ ) and Norfolk (4 by $P_{\mathrm{G}}, 6$ by $\left.P_{\text {Fish }}\right)$, often when paired with samples from Cornwall (Table 2).

At a fine scale within Cornwall and the Isles of Scilly, overall $F_{\mathrm{ST}}$ was $0.0005 \quad\left(P_{\mathrm{G}}=0.13 ; 95 \%\right.$ $\mathrm{CI}=-0.002$ to $\left.0.003 ; P_{\text {Fish }}=0.019\right)$ and overall $D$ was $0.0006\left(P_{\mathrm{G}}=0.43 ; 95 \% \mathrm{CI}=-0.005\right.$ to 0.007$)$, both with confidence intervals overlapping zero. The maximum pairwise $F_{\mathrm{ST}}$ was 0.012 , with no comparisons significant after FDR control, and only five $<0.05$ by $P_{\text {Fish }}$ (Table 2). Among loci, the total number of alleles ranged from 8 to 20, and the locus HGB6 provided the greatest degree of heterogeneity across all samples via both measures of differentiation $\left(F_{\mathrm{ST}}=\right.$

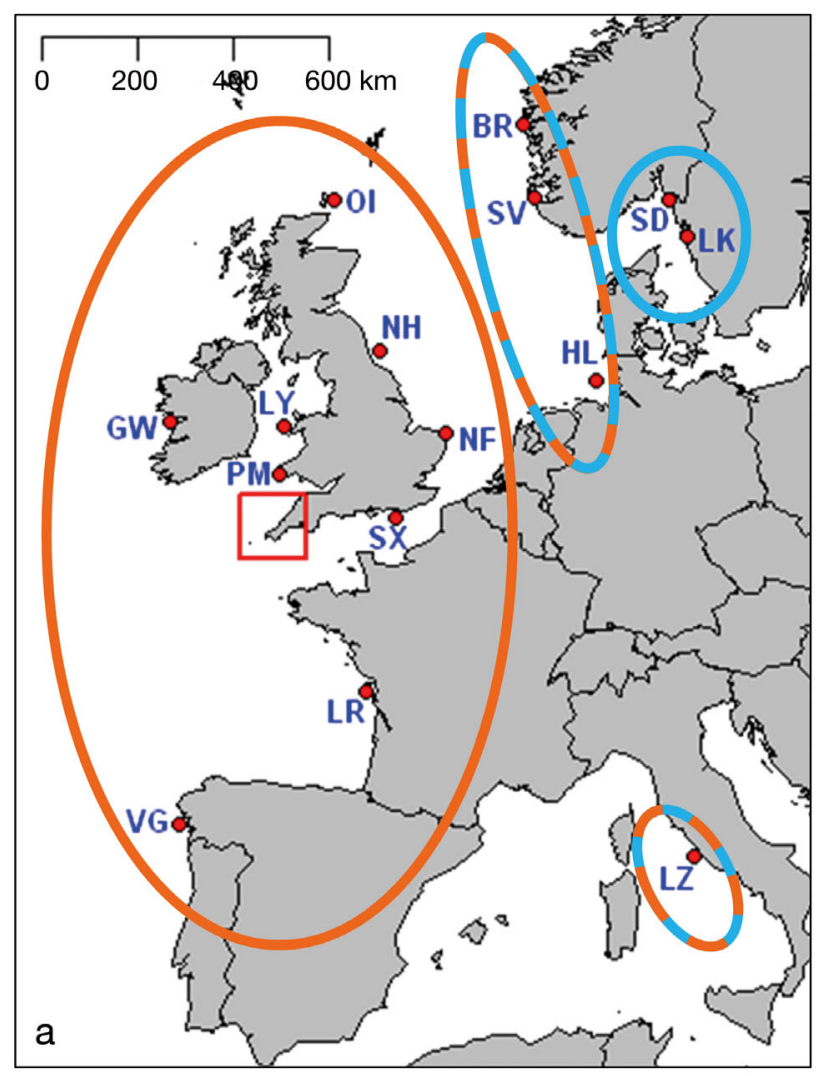

$0.034, D=0.064 ;$ Table S1). Along with HGB6, 4 other loci (HGB4, HGC103, HGC6 and HGD129) had confidence intervals for global $D$ that did not overlap zero (Table S1).

At a European level, consistent population structure among samples was detected by STRUCTURE outputs (Fig. 2), although only when coalescent algorithms featured a priori information of sample composition, another indication that the inferred structure is weak (either as a result of genuinely subtle divergence or insufficient markers or individuals; Hubisz et al. 2009). Differentiation was absent when spatial priors were omitted, when Swedish samples included only individuals re-genotyped during this study and when fine-scale samples from Cornwall were run in isolation (Fig. S3). All divergent clustering was a result of differentiation at 2 of the 14 loci: HGB6 and HGC111 (Fig. S4). Evanno's delta- $K$ suggested that $K=2$ was the optimum number of clusters among the full dataset, although the likelihood and standard deviation of coalescence changed sharply only beyond $K=4$ (Fig. S2). However, increasing the number of clusters beyond $K=2$ was not informative in revealing any additional population clusters (Fig. S5), and $K=2$ provided the greatest convergence proportion (0.92 to 0.95 ) for any value of $K$ (Figs. 2b \& S4).

Heterogeneity in cluster stratification showed that there was a clear trend for the 2 samples from western Sweden to be differentiated from those of a main Atlantic cluster featuring all samples from Western Europe, including the UK. Samples from the eastern North Sea from Norway and Germany appeared to be a mixture of these 2 main clusters, as did, unexpectedly, the single Mediterranean sample from Italy. Mean cluster proportions across iterations showed that all UK and Atlantic samples were $>68 \%$ assigned to Cluster 1 (orange; Fig. 2), while samples from the eastern North Sea (except Stavanger) and Italy were $>60 \%$ assigned to Cluster 2 (blue; Fig. 2). The sample from Stavanger was the most evenly assigned, with marginally greater (55\%) assignment

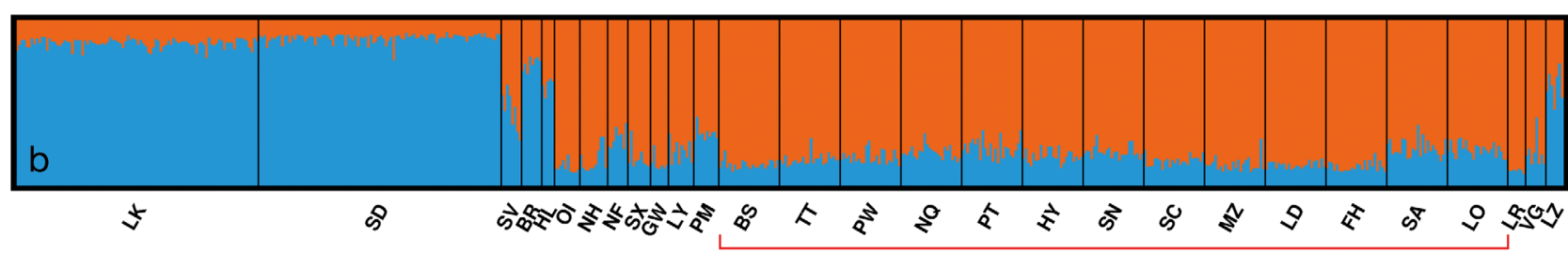

Fig. 2. Assignment and map of population clusters. (a) Sample groupings as indicated by colour composition of individual samples (vertical bands) in (b). (b) Distruct plot of 5 converged iterations of $K=2$ using a priori location data. The inset red area in (a) and red underlined section in (b) denote fine-scale samples from Cornwall, UK. See Table 1 for abbreviated sample names 


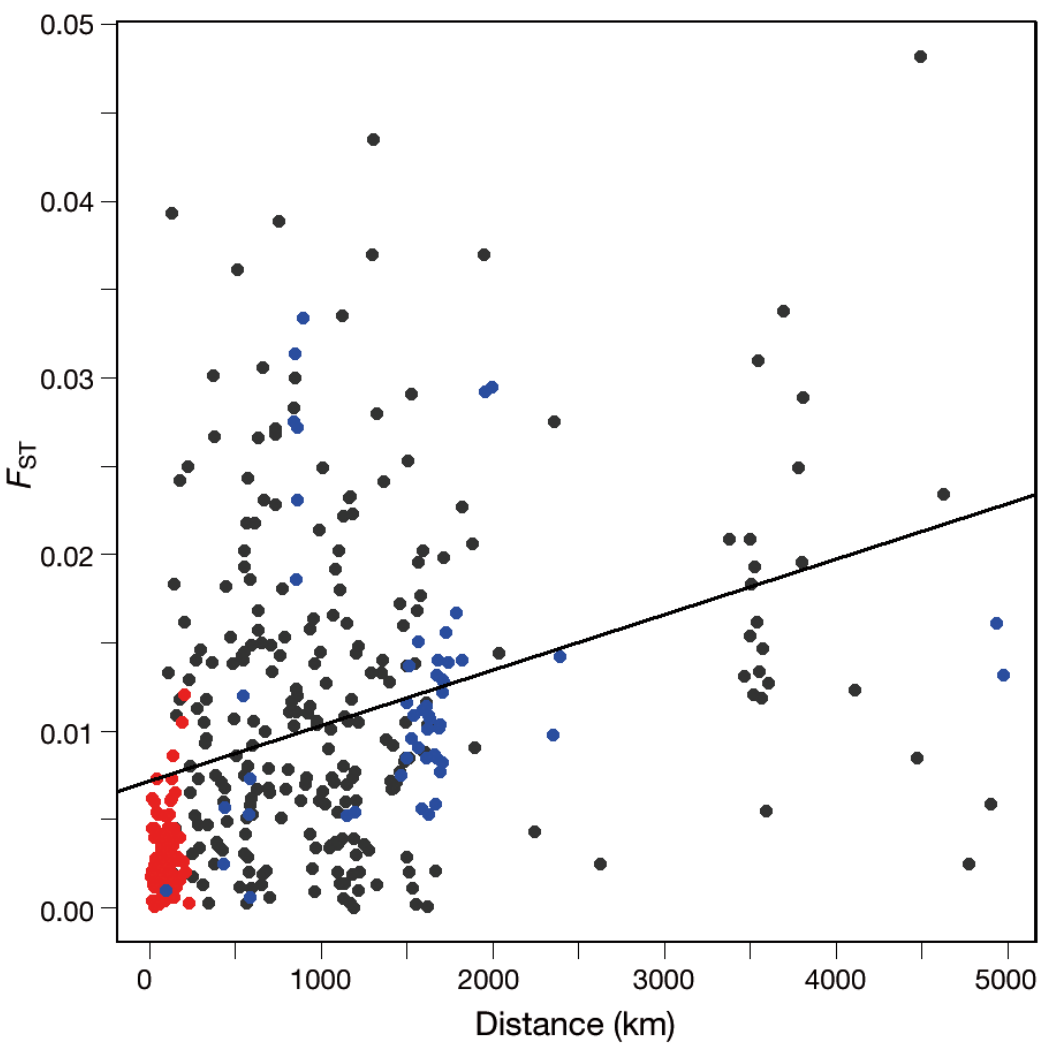

Fig. 3. Regression between pairwise geographic $(\mathrm{km})$ and genetic $\left(F_{\mathrm{ST}}\right)$ distance, for which a significant correlation from a 10000-permutation Mantel test suggests samples demonstrate IBD $\left(r^{2}=0.129, p=0.0003\right)$. Pairwise finescale samples from Cornwall, UK, are shown in red, and all samples paired with the 2 samples from Sweden are shown in blue. Negative values of $F_{\mathrm{ST}}$ are converted to positives, although retaining negative values did not alter significance and had negligible effect on explanatory power $\left(\mathrm{r}^{2}=0.136\right)$

$(\mathrm{r}=0.41 ; \mathrm{p}=0.17$; neither data presented), although this may simply result from the lack of power attributed to the latter from reduced pairwise comparisons (10, vs. 253 for the Atlantic cluster).

\section{Power to detect genetic structure}

POWSIM estimated that there was high statistical power to detect overall genetic differentiation, even at low $F_{\mathrm{ST}}$ (Fig. 4). With the sampling effort we applied, there was significant power $(\beta \mathrm{p}<0.05)$ to reject fine-scale homogeneity when overall $F_{\mathrm{ST}}$ was $>0.0035$, and to reject broad-scale homogeneity when overall $F_{\text {ST }}$ was $>0.0025$ (Fig. 4a). The probability of falsely rejecting overall genetic homogeneity was low at both sampling scales ( $\alpha \mathrm{p}<0.08)$. Although POWSIM estimated $\alpha$ error rates slightly greater than 0.05 , this is normal for multi-allelic, skewed frequency markers values, and rates closer to zero are associated with datasets providing very low resolution (Ryman et al. 2006). Restricting the size of all samples to that of reduced European outgroups ( $\mathrm{n}=8$ ) still provided $95 \%$ confidence in the rejection

to Cluster 1. The mean allele frequency divergence between clusters was 0.013 , and the mean $H_{\mathrm{E}}$ was 0.66 for Cluster 1 and 0.69 for Cluster 2. The global AMOVA showed that $\sim 1 \%$ of the total genetic variation arises among the 2 inferred clusters, 5 times more variation than occurs among the samples within each cluster (Table S3). Even when analysing divergent Swedish samples separately, all markers generally displayed selective neutrality (Fig. S6).

IBD was detected at a European level, with geographic and genetic distances being significantly correlated $(r=0.129 ; p=0.0003$; Fig. 3 ), and was only marginally non-significant at a fine-scale level within Cornwall ( $\mathrm{r}=0.063 ; \mathrm{p}=0.06)$. Untangling whether genetic heterogeneity arises from IBD or actual barriers to gene flow is problematic, but testing IBD for each identified population cluster instead of globally allows for the effect of hierarchical structure (Meirmans 2012). When analysing clusters individually, IBD was significant within the Atlantic cluster $(\mathrm{r}=$ 0.10; $p=0.002$ ) but not the eastern North Sea cluster of genetic homogeneity whenever overall differentiation reached $F_{\mathrm{ST}}=0.0075$.

Within Cornwall, POWSIM estimated that there was significant power ( $>95 \%$ ) to detect pairwise differentiation whenever $F_{\mathrm{ST}}>0.014$. However, even where expected pairwise $F_{\mathrm{ST}}=0.025$ between any sample from Cornwall and any small European outgroup, the power to detect differentiation was nonsignificant (88\%), and between 2 small European outgroups it was only $52 \%$ (Fig. 4b). POWSIM estimated that genetic drift was expected to generate differentiation of $F_{\mathrm{ST}}=0.00025$ per generation at $N_{\mathrm{e}}=2000$, and of $F_{\mathrm{ST}}=0.00005$ per generation at $N_{\mathrm{e}}=10000$ (Fig. $4 \mathrm{a}$ ). When reducing the sizes of the 2 Swedish samples to match others used in this study, there was a clear loss of coverage of the total alleles detected. Sample sizes from Cornwall $(n=24)$ detected an estimated $79 \%$ of the allelic diversity present in samples of 96 individuals, while the mean size of broad-scale samples outside Sweden $(n=8)$ detected less than $64 \%$ of the alleles apparent in 96 individuals (Fig. S7). 


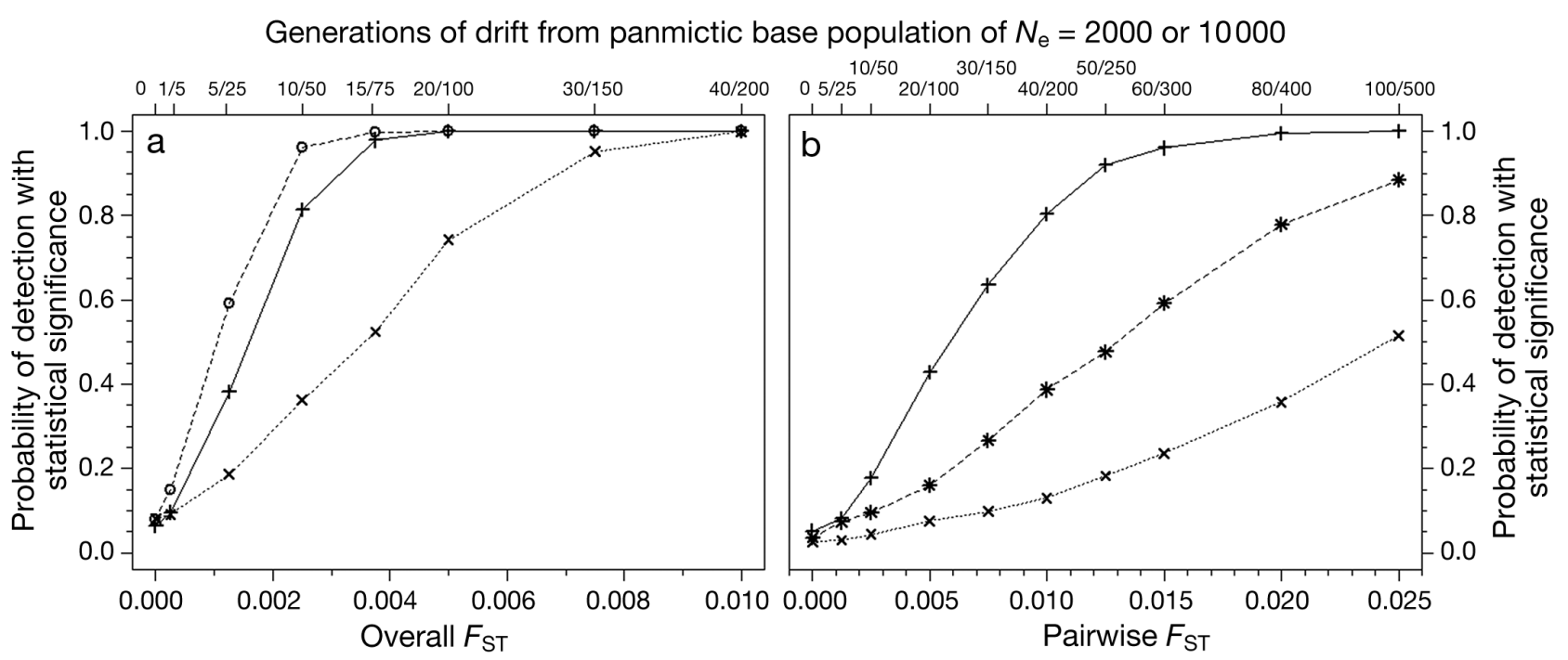

Fig. 4. Estimated probability of detecting significant genetic differentiation. Results of POWSIM tests of the power of the microsatellite panel to detect significant genetic differentiation (a) overall and (b) between pairwise samples, after a simulated base population undergoes genetic drift. Probabilities of detection express p-values of Fisher's exact tests $(\mathrm{df}=28)$, calculated as the proportion of (a) 5000 or (b) 1000 simulations that provided significant power ( $p>0.05$ ) to reject the null hypothesis of genetic homogeneity. Where generations of drift is zero $\left(F_{\mathrm{ST}}=0.0000\right)$, p-values equate to the probability of falsely rejecting genetic homogeneity. In (a), data points denote fine-scale as sampled (+), broad-scale as sampled (O) and broad-scale with mean minimum sample sizes $(x)$. In (b), data points denote pairwise comparisons as sampled at a fine-scale $(+)$, between finescale as sampled and broad-scale with mean minimum sample sizes (*), and at a broad-scale with mean minimum sample sizes $(\times)$. $N_{\mathrm{e}}$ : effective population size

\section{DISCUSSION}

Our results, obtained from the most geographically extensive appraisal of contemporary population structure conducted in this species to date, provide an indication that European lobsters do not exhibit spatial genetic structure throughout large areas of the species' range, but that genetic heterogeneity is apparent within their distribution. This heterogeneity is evidenced by weak but consistent differentiation between samples from the Swedish Skagerrak and those from open Atlantic areas to the west. There was also a strong association between genetic and geographic distances, suggesting that larval dispersal, the presumed mechanism of primary connectivity (Huserbråten et al. 2013), may become increasingly limited beyond adjacent regions. However, we found no evidence of substantial genetic differences between geographically distant samples throughout the open Atlantic portion of the range. This result aligns with the previous findings of Triantafyllidis et al. (2005), who detected negligible differentiation in mitochondrial DNA haplotypes among all samples from the UK and the French and Iberian Atlantic, but may be a consequence of lack of power to detect weak differentiation, caused by small sample sizes in our broad-scale analysis.
Our results at a fine geographic scale resemble those obtained by Huserbråten et al. (2013), who detected no substantial differentiation throughout a comparable expanse of the Skagerrak, as well as Watson et al. (2016), who found no genetic structure across parts of the Irish and Celtic Seas. Our findings indicate that hatchery releases in Cornwall, southwestern UK, are unlikely to exceed the spatial extent of population connectivity by natural dispersal or compromise natural spatial structuring.

\section{Broad-scale population differentiation}

The strongest indication of restricted gene flow within Homarus gammarus was found among samples from western Sweden, where broad-scale sampling was concentrated. The phylogeographic study of $H$. gammarus by Triantafyllidis et al. (2005) found no differentiation between a sample from western Sweden and those from the UK/Atlantic, although this was based on mitochondrial DNA, which may underestimate contemporary divergence (e.g. Monsen \& Blouin 2003). A fundamental difference between samples we analysed from Sweden and those we analysed from elsewhere is that the majority of Swedish lobsters were genotyped by other resear- 
chers rather than during this study. Although it cannot be discounted that the observed genetic divergence may have arisen from differences in allelic scoring, the re-analysis of several individuals should have calibrated the 2 datasets. Significant clustering variation was based on a marker that showed no ambiguity in allele sizing or discrepancy between datasets, therefore the observed divergence of Swedish lobsters seems genuine.

Differentiation between Skagerrak and other populations makes sense biophysically: Baltic Sea discharge means there is a mean annual net outflow of 450 to $500 \mathrm{~km}^{3}$ from the Skagerrak into the North Sea (Omstedt et al. 2004), so Skagerrak lobster populations at the boundary of the species' range may experience a net deficit of larval migration due to asymmetric dispersal (e.g. Pringle et al. 2011). Perhaps, more importantly, prevailing currents circulate the Skagerrak, hydrological conditions which could promote the extensive larval dispersal and genetic homogeneity reported within the region (Huserbråten et al. 2013) while also creating weak differentiation from Atlantic populations through regional larval retention. In the same way, Atlantic cod Gadus morhua are generally self-recruiting in the Skagerrak, with comprehensive genetic stock divergence inhibited only by occasional influxes of larvae from North Sea populations (Knutsen et al. 2004). Combining the findings of Huserbråten et al. (2013) and those of the population clustering from our analysis, microsatellite DNA evidences a discrete lobster population unit in the Skagerrak/Kattegat region, with connectivity to the UK/Atlantic maintained largely via indirect gene flow through intermediary subpopulations of the eastern North Sea.

Not all our results fit this narrative neatly, however. Cluster analysis showed that the sample from Stavanger (collected from the nearby Kvitsøy archipelago), aligned towards the Swedish group less well than other samples of the eastern North Sea from Bergen and Helgoland. It is possible that this might be an artefact of hatchery-induced gene flow, as a small fraction of broodstock initially used to restock the heavily depleted Kvitsøy area was imported from Scotland (Agnalt et al. 1999, Jørstad \& Farestveit 1999).

Another unexpected grouping involved the sample from Lazio, western Italy, which clustered with the Scandinavian samples almost $5000 \mathrm{~km}$ away. Confidence in the reliability of this result is not high, but cluster definition was consistent between all individuals. The area from which the Italian samples were collected has recently undergone hatchery stocking
(Ellis et al. 2015a), but broodstock were sourced locally and no juveniles were released prior to the collection of tissues for our analysis (R. Cimmaruta pers. comm.). An alternative, anthropogenic explanation may be the escape of adult lobsters (or their larvae) from tanks or cages in or beside the sea, following their import (for seafood) from northern Europe, the mechanism presumed to be responsible for the presence of American lobsters $H$. americanus throughout many coastal European waters (e.g. Jørstad et al. 2007).

The genetic differentiation previously detected in H. gammarus occurs in populations located towards the limits of the species' distribution, with discrete biological units being previously identified in northern Norway and the Aegean Sea (Jørstad \& Farestveit 1999, Jørstad et al. 2004, Triantafyllidis et al. 2005). Increased genetic drift and fragmentation of population structure towards range margins is often a consequence of relatively infrequent immigration and emigration (Hellberg 2009). The geographic samples we found to be differentiated from Atlantic populations also share a recent history of heavy depletion by recruitment overfishing (Agnalt et al. 1999, Schmalenbach et al. 2011), which typically accelerates genetic drift (Waples \& England 2011). However, genetic divergence caused by drift via limited gene flow is usually characterised by a relative reduction in genetic diversity (Alleaume Benharira et al. 2006), which was not detected in Swedish lobster samples. Divergence of these fringe populations may instead result from adaptation to environmental conditions that are at the limits of the species' tolerance (isolation by adaptation; Orsini et al. 2013).

\section{Fine-scale population connectivity}

We found no evidence of significant genetic differentiation amongst $H$. gammarus collected across Cornwall and the Isles of Scilly, an area throughout which hatchery stock enhancement is currently undertaken (Ellis et al. 2015a). Marginally non-significant differentiation and IBD suggests that the existence of some weak spatial heterogeneity cannot be completely discounted. However, fine-scale samples comprised enough individuals to represent population allele frequencies relatively accurately (Hale et al. 2012) and to detect robust differentiation, had it existed.

Stock enhancement commenced in Cornwall in 2002, with an average of 12500 hatchery juveniles 
released annually up to 2013 (Ellis et al. 2015a). Even at optimistic projections of survival to fishery recruitment (e.g. 30 to $40 \%$; Schmalenbach et al. 2011), such numbers equate to fewer than $0.25 \%$ of the $\sim 2$ million lobsters comprising the regional stock (Cefas 2015). It is therefore highly unlikely that the observed homogeneity in allelic diversity is a consequence of any recent erosion of spatial structure by hatchery stocking. Instead, the low levels of genetic drift detected $\left(F_{\mathrm{ST}}=0.00005\right.$ per generation when $N_{\mathrm{e}}$ $=10000$ ) are almost certainly counteracted by gene flow. Unless $N_{\mathrm{e}}$ is drastically reduced by bottlenecking, genetic drift is slow, so a low effective number of migrants $\left(N_{\mathrm{m}}\right)$ generate sufficient gene flow to prevent populations becoming differentiated (Waples \& England 2011). Even in isolated subpopulations, 1 to 10 migrants per generation typically inhibit strong divergence (Mills \& Allendorf 1996), and although calculating gene flow from measures of differentiation gives only a tentative approximation (Waples 1998, Whitlock \& McCauley 1999), the overall $F_{\mathrm{ST}}$ in Cornwall corresponds to 500 migrants entering the effective population per generation (as per Wright's island model, $\left.N_{\mathrm{m}}=\left[\left(1 / F_{\mathrm{ST}}\right)-1\right] / 4\right)$.

\section{IBD}

Low values of $F_{\mathrm{ST}}$ and high genetic connectivity in marine species does not necessarily correspond to an absence of population structure (Waples 1998). Triantafyllidis et al. (2005) previously detected significant broad-scale IBD among $H$. gammarus populations, and our results provide further evidence that dispersal may be restricted throughout the species' range. High site fidelity has been observed among adult lobsters across multiple locations (Øresland \& Ulmestrand 2013, Wiig et al. 2013, Skerritt et al. 2015) and the pelagic larval duration is a relatively modest 2 to 4 wk under natural thermal niches (Schmalenbach \& Franke 2010).

If the genetic homogeneity between geographically disparate samples that our results evidence is a true reflection of population connectivity, then gene flow most adequately fits a stepping-stone model (Kimura \& Weiss 1964). Stepping-stone structure is often exhibited where marine populations are fragmented by restriction to patchy habitats (e.g. Lejeusne \& Chevaldonné 2006), and this appears to fit the preference for shelter-providing rocky substrata of adult Homarus (Wahle et al. 2013). It may be that all differentiation we observe is a consequence of IBD.

\section{Methodological power and resolution}

More extensive differentiation in $H$. gammarus populations than we have identified might be revealed using more genetic markers, markers associated with adaptation, more samples and particularly a greater number of individuals within samples. The ratio of statistical signal to noise is often prohibitively low among marine species when genetic samples comprise few individuals (Waples 1998), with samples obviously prone to yielding calculations of allele frequencies and total heterozygosity unreflective of the wider population, which often biases and inflates estimates of pairwise differentiation (Hale et al. 2012).

Our power analyses produced clear evidence that many geographic samples contributing to the study were too small to facilitate any conclusive interpretation of broad-scale population genetic structure, other than the absence of extreme differentiation. The extent of $H$. gammarus population genetic structure would clearly be more robustly represented by a greater number of individuals among all geographic samples outside of Cornwall and Sweden, and also by more geographic samples across the southern part of the range. Although moderate differentiation $\left(F_{\mathrm{ST}}=0.01\right)$ was estimated to be detectable with significant power at an overall level among small samples (<12 individuals), only in a minority of pairwise cases $(13 \%)$ was power deemed sufficient to detect such divergence with significance.

Methods of genotyping by sequencing (GBS) have become increasingly favoured in the study of population structure, and have proved to be especially useful in detecting extremely small signals of differentiation among weakly structured marine species (Willette et al. 2014). One recent example is the determination of population structure in $H$. americanus, the nearest relative of $H$. gammarus. Kenchington et al. (2009) used 13 microsatellites to assess population structure in $H$. americanus, identifying 2 population clusters, divided into the northern and southern portions of the species' range. Since then, Benestan et al. (2015) confirmed this broad-scale divergence using >8000 neutral single nucleotide polymorphisms, but also discovered robust evidence for IBD and hierarchical fine-scale differentiation. The resolution provided by GBS has facilitated the identification of current flows and adaptation to thermal niches as potential drivers of structured genetic variation in $H$. americanus (Benestan et al. 2016), and we recommend that future studies of population structure in the European lobster adopt this approach. 


\section{Implications for fisheries management and hatchery stocking}

To date, a lack of data on population structure and connectivity has prevented the informed definition of $H$. gammarus stock units and therefore the implementation of effective management at spatial scales that reflect stock boundaries (Wahle et al. 2013). Until this is resolved, national or regional legislations aimed at restricting fishing (e.g. closed seasons, closed areas, gear restrictions, landing bans on vnotched or ovigerous lobsters, maximum landing sizes and extended minimum landing sizes; Ellis et al. 2015a) have a significant role to play in the conservation of European lobster populations, as our evidence of IBD suggests that recruitment is driven, at least partially, by local spawning stock biomass. By contrast, evidence of highly connected proximal populations suggests that localised overfishing may cause surrounding areas to suffer reduced recruitment. Similarly, where local spawning stock biomass can be increased by effective fisheries management, larval dispersal may well extend recruitment benefits to adjacent regions.

The same implication applies to hatchery stocking, given that cultured lobsters produce viable offspring (Agnalt 2008, Jørstad et al. 2009); increased abundance and recruitment from hatchery interventions may extend far beyond the immediate areas of releases over multiple generations. Any unintended impacts of stocking to the wild stock, such as the introduction of maladapted traits (e.g. Araki et al. 2007, Christie et al. 2012a) may also be widely dispersed. However, negative genetic impacts of hatchery releases are most common and most damaging where natural stock is depleted, extensively structured and demonstrates considerable adaptation to localised environments (Lorenzen et al. 2012), all of which can be discounted with reasonable confidence for lobsters throughout Cornwall and the Isles of Scilly. Overall, we found high gene flow throughout this area, and no evidence that current hatchery protocols lead to juvenile lobsters being released beyond the spatial extent of natural dispersal, although long-term monitoring approaches (i.e. before-after control-impact; e.g. Moland et al. 2013) are required to properly demonstrate the impacts of lobster stocking (Ellis et al. 2015a).

Genetic evidence has previously revealed distinct, isolated, self-recruiting $H$. gammarus sub-populations (e.g. in northern Norway; Jørstad \& Farestveit 1999, Jørstad et al. 2004), but our results indicate that such strong differentiation is probably rare. This study has contributed considerable information on lobster population genetics, and suggests $H$. gammarus populations may be well connected without being panmictic. A further assessment which tests more markers on more lobsters (i.e. comparable to that of Benestan et al. 2015, 2016) would be a vital resource upon which to base fisheries management and hatchery release strategies. Until population genetic structure has been assessed with such rigour, we recommend a precautionary approach to hatchery stocking programmes whereby broodstock are locally sourced and juveniles are not imported from distant areas without robust empirical evidence of genetic homogeneity between regions.

Data availability. DORIS is available through Google Play app store, and the website can be accessed at http:// dorismap.exeter.ac.uk/. All source code is open source and available for free at http://github.com/nebogeo/doris/. The full dataset of genotypes for up to 15 microsatellite loci from 612 individuals across 28 spatial samples is available on Dryad at http://dx.doi.org/10.5061/dryad.v176m.

Acknowledgements. This research was supported by Lobster Grower 2, a 3 yr project funded by Innovate-UK (TS/ N006097/1) and BBSRC (BB/N013891/1) under an AgriTech Catalyst Industrial Stage Award. We are also greatly appreciative of the studentship funding provided by the European Social Fund and of the grant awarded by the Fishmonger's Company, UK, both of which made the work possible. We are extremely grateful to Carl André for the provision of genotype data, and to the many researchers and stakeholders who provided lobster DNA, tissues or sampling opportunities, including Alan Fearless, Alexandra Kraberg, Andrew Spencer, Ann-Lisbeth Agnalt, Brian Bate, Callum Greenhalgh, Cameron and Ivor Henry, Chris Brett, Chris Earl, David Evans, Dennis Gowland, Eva Farestveit, Margaret and Galway Bay Seafoods, Gerald Northy, Gonzalo Pérez Benavente, Hawkins Fish, John Rogers, Nick Samujlik and Jonas Seafood, Louis Mitchell, Margret Krüss and the specimen supply service at the AWI Helgoland Biological Institute, Jim and Monteum Limited, Natalie Hold, Ned and Tim Bailey, Phil Shannon, Roberta Cimmaruta and CISMAR, and Tony Bicknell. We are also indebted to Cornwall Inshore Fisheries and Conservation Authority and the Marine Management Organisation for granting permissions to carry out sampling, and to Dave Griffiths and FoAM Kernow for the creation of DORIS, an in situ lobster sampling app.

\section{LITERATURE CITED}

Addison JT, Bannister RCA (1994) Re-stocking and enhancement of clawed lobster stocks: a review. Crustaceana 67:131-155

Agnalt AL (2008) Fecundity of the European lobster (Homarus gammarus) off southwestern Norway after stock enhancement: Do cultured females produce as many eggs as wild females? ICES J Mar Sci 65:164-170 
Agnalt AL, van der Meeren GI, Jørstad KE, Næess H and others (1999) Stock enhancement of European lobster (Homarus gammarus): a large-scale experiment off south-western Norway (Kvitsøy). In: Howell B, Moksness E, Svåsand T (eds) Stock enhancement and sea ranching. Fishing News Books Ltd, Farnham, p 401-419

Albrecht GT, Valentin AE, Hundertmark KJ, Hardy SM (2014) Panmixia in Alaskan populations of the snow crab Chionoecetes opilio (Malacostraca: Decapoda) in the Bering, Chukchi, and Beaufort Seas. J Crustac Biol 34: 31-39

Alleaume Benharira M, Pen IR, Ronce O (2006) Geographical patterns of adaptation within a species' range: interactions between drift and gene flow. J Evol Biol 19: 203-215

André C, Knutsen H (2010) Development of twelve novel microsatellite loci in the European lobster (Homarus gammarus). Conserv Genet Resour 2:233-236

Antao T, Lopes A, Lopes RJ, Beja-Pereira A, Luikart G (2008) LOSITAN: a workbench to detect molecular adaptation based on a $F_{\mathrm{st}}$-outlier method. BMC Bioinformatics 9:323

Araki H, Cooper B, Blouin MS (2007) Genetic effects of captive breeding cause a rapid, cumulative fitness decline in the wild. Science 318:100-103

* Ayllon F, Martinez JL, Garcia-Vazquez E (2006) Loss of regional population structure in Atlantic salmon, Salmo salar L., following stocking. ICES J Mar Sci 63: 1269-1273

Babbucci M, Buccoli S, Cau A, Cannas R and others (2010) Population structure, demographic history, and selective processes: contrasting evidences from mitochondrial and nuclear markers in the European spiny lobster Palinurus elephas (Fabricius, 1787). Mol Phylogenet Evol 56: 1040-1050

* Benestan L, Gosselin T, Perrier C, Sainte Marie B, Rochette R, Bernatchez L (2015) RAD genotyping reveals fine scale genetic structuring and provides powerful population assignment in a widely distributed marine species; the American lobster (Homarus americanus). Mol Ecol 24:3299-3315

Benestan L, Quinn BK, Maaroufi H, Laporte M and others (2016) Seascape genomics provides evidence for thermal adaptation and current mediated population structure in American lobster (Homarus gammarus). Mol Ecol 25: 5073-5092

Benjamini Y, Yekutieli D (2001) The control of the false discovery rate in multiple testing under dependency. Ann Stat 29:1165-1188

Bilodeau AL, Felder DI, Neigel JE (2005) Population structure at two geographic scales in the burrowing crustacean Callichirus islagrande (Decapoda, Thalassinidea): historical and contemporary barriers to planktonic dispersal. Evolution 59:2125-2138

Blanco Gonzalez E, Aritaki M, Knutsen H, Taniguchi N (2015) Effects of large-scale releases on the genetic structure of Red Sea bream (Pagrus major, Temminck et Schlegel) populations in Japan. PLOS ONE 10:e0125743

Burton RS (1994) Inferring the genetic structure of marine populations: a case study comparing allozyme and DNA sequence data. CCOFI Rep 35:52-61

Cefas (2015) Lobster (Homarus gammarus). Cefas Stock Status Report 2014. https://www.gov.uk/government/ uploads/system/uploads/attachment_data/file/462251/
2014_Lobster_assessments.pdf

Chapuis MP, Estoup A (2007) Microsatellite null alleles and estimation of population differentiation. Mol Biol Evol 24: 621-631

Christie MR, Marine ML, French RA, Blouin MS (2012a) Genetic adaptation to captivity can occur in a single generation. Proc Natl Acad Sci USA 109:238-242

Christie MR, Marine ML, French RA, Waples RS, Blouin MS (2012b) Effective size of a wild salmonid population is greatly reduced by hatchery supplementation. Heredity 109:254-260

*Do C, Waples RS, Peel D, Macbeth GM, Tillett BJ, Ovenden JR (2014) NeEstimator V2: re-implementation of software for the estimation of contemporary effective population size $\left(N_{\mathrm{e}}\right)$ from genetic data. Mol Ecol Resour 14: 209-214

*Earl DA, von Holdt BM (2012) STRUCTURE HARVESTER: a website and program for visualizing STRUCTURE output and implementing the Evanno method. Conserv Genet Resour 4:359-361

Ellis CD, Hodgson DJ, Daniels CL, Boothroyd DP, Bannister RCA, Griffiths AGF (2015a) European lobster stocking requires comprehensive impact assessment to determine fishery benefits. ICES J Mar Sci 72(Suppl 1): i35-i48

Ellis CD, Knott H, Daniels CL, Witt MJ, Hodgson DJ (2015b) Geographic and environmental drivers of fecundity in the European lobster (Homarus gammarus). ICES J Mar Sci 72(Suppl 1):i91-i100

* Ellis CD, Hodgson DJ, André C, Knutsen H, Sørdalen TK, Griffiths AGF (2015c) Genotype reconstruction of paternity in European lobsters (Homarus gammarus). PLOS ONE 10:e0139585

Evanno G, Regnaut S, Goudet J (2005) Detecting the number of clusters of individuals using the software STRUCTURE: a simulation study. Mol Ecol 14:2611-2620

Excoffier L, Lischer HEL (2010) Arlequin suite ver 3.5: a new series of programs to perform population genetics analyses under Linux and Windows. Mol Ecol Resour 10: 564-567

Falush D, Stephens M, Pritchard JK (2007) Inference of population structure using multilocus genotype data: dominant markers and null alleles. Mol Ecol Notes 7: 574-578

*Gerlach G, Jueterbock A, Kraemer P, Deppermann J, Harmand $P$ (2010) Calculations of population differentiation based on $G_{\mathrm{ST}}$ and $D$ : forget $G_{\mathrm{ST}}$ but not all of statistics! Mol Ecol 19:3845-3852

Goudet J (2001) FSTAT: a program to estimate and test gene diversities and fixation indices (version 2.9.3; updated 2001 from Goudet, 1995). www2.unil.ch/popgen/softwares/ fstat.htm

* Hale ML, Burg TM, Steeves TE (2012) Sampling for microsatellite-based population genetic studies: 25 to 30 individuals per population is enough to accurately estimate allele frequencies. PLOS ONE 7:e45170

Hellberg ME (2009) Gene flow and isolation among populations of marine animals. Annu Rev Ecol Evol Syst 40: 291-310

*Hoskin MG, Coleman RA, von Carlshausen E, Davis CM (2011) Variable population responses to the establishment of a temperate no-take zone. Can J Fish Aquat Sci 68:185-200

Hubisz MJ, Falush D, Stephens M, Pritchard JK (2009) Inferring weak population structure with the assistance of 
sample group information. Mol Ecol Resour 9:1322-1332

Huserbråten MBO, Moland E, Knutsen H, Olsen EM, André C, Stenseth NC (2013) Conservation, spillover and gene flow within a network of Northern European marine protected areas. PLOS ONE 8:e73388

Jorde PE, Søvik G, Westgaard JI, Albretsen J and others (2015) Genetically distinct populations of northern shrimp, Pandalus borealis, in the North Atlantic: adaptation to different temperatures as an isolation factor. Mol Ecol 24:1742-1757

Jørstad KE, Farestveit E (1999) Population genetic structure of lobster (Homarus gammarus) in Norway, and implications for enhancement and sea-ranching operation. Aquaculture 173:447-457

Jørstad KE, Prodöhl PA, Agnalt AL, Hughes M and others (2004) Sub-arctic populations of European lobster, Homarus gammarus, in northern Norway. Environ Biol Fishes 69:223-231

Jørstad KE, Prodöhl PA, Agnalt AL, Hughes M, Farestveit E, Ferguson AF (2007) Comparison of genetic and morphological methods to detect the presence of American lobsters, Homarus americanus H. Milne Edwards, 1837 (Astacidea: Nephropidae), in Norwegian waters. Hydrobiologia 590:103-114

Jørstad KE, Kristiansen TS, Farestveit E, Agnalt AL and others (2009) Survival of laboratory reared juvenile European lobster (Homarus gammarus) from three brood sources in southwestern Norway. NZ J Mar Freshw Res 43:59-68

Jost L (2008) $G_{\mathrm{ST}}$ and its relatives do not measure differentiation. Mol Ecol 17:4015-4026

Jost L (2009) $D$ vs. $G_{\mathrm{ST}}$ : response to Heller and Siegismund (2009) and Ryman and Leimar (2009). Mol Ecol 18: 2088-2091

Kenchington E, Heino M, Nielsen EE (2003) Managing marine genetic diversity: time for action. ICES J Mar Sci 60: 1172-1176

Kenchington EL, Harding GC, Jones MW, Prodöhl PA (2009) Pleistocene glaciation events shape genetic structure across the range of the American lobster, Homarus americanus. Mol Ecol 18:1654-1667

Kimura M, Weiss GH (1964) The stepping stone model of population structure and the decrease of genetic correlation with distance. Genetics 49:561-576

Knutsen H, André C, Jorde PE, Skogen MD, Thuróczy E, Stenseth NC (2004) Transport of North Sea cod larvae into the Skagerrak coastal populations. Proc R Soc B 271: 1337-1344

Kopelman NM, Mayzel J, Jakobsson M, Rosenberg NA, Mayrose I (2015) Clumpak: a program for identifying clustering modes and packaging population structure inferences across $K$. Mol Ecol Resour 15:1179-1191

Koskinen MT, Sundell P, Piironen J, Primmer CR (2002) Genetic assessment of spatiotemporal evolutionary relationships and stocking effects in grayling (Thymallus thymallus, Salmonidae). Ecol Lett 5:193-205

Lejeusne C, Chevaldonné P (2006) Brooding crustaceans in a highly fragmented habitat: the genetic structure of Mediterranean marine cave dwelling mysid populations. Mol Ecol 15:4123-4140

Lorenzen K, Leber KM, Blankenship HL (2010) Responsible approach to marine stock enhancement: an update. Rev Fish Sci 18:189-210

Lorenzen K, Beveridge MCM, Mangel M (2012) Cultured fish: integrative biology and management of domestica- tion and interactions with wild fish. Biol Rev Camb Philos Soc 87:639-660

* Lougheed SC, Gibbs HL, Prior KA, Weatherhead PJ (2000) A comparison of RAPD versus microsatellite DNA markers in population studies of the Massasauga rattlesnake. J Hered 91:458-463

Meirmans PG (2012) The trouble with isolation by distance. Mol Ecol 21:2839-2846

* Mills LS, Allendorf FW (1996) The one migrant per generation rule in conservation and management. Conserv Biol 10:1509-1518

* Moland E, Olsen EM, Knutsen H, Garrigou P and others (2013) Lobster and cod benefit from small scale northern marine protected areas: inference from an empirical before-after control-impact study. Proc R Soc B 280: 20122679

* Monsen KJ, Blouin MS (2003) Genetic structure in a montane ranid frog: restricted gene flow and nuclear-mitochondrial discordance. Mol Ecol 12:3275-3286

\%omstedt A, Elken J, Lehmann A, Piechura J (2004) Knowledge of the Baltic Sea physics gained during the BALTEX and related programmes. Prog Oceanogr 63:1-28

Øresland V, Ulmestrand M (2013) European lobster subpopulations from limited adult movements and larval retention. ICES J Mar Sci 70:532-539

Orsini L, Vanoverbeke J, Swillen I, Mergeay J, Meester L (2013) Drivers of population genetic differentiation in the wild: isolation by dispersal limitation, isolation by adaptation and isolation by colonization. Mol Ecol 22: 5983-5999

Pampoulie C, Skirnisdottir S, Hauksdottir S, Olafsson K and others (2011) A pilot genetic study reveals the absence of spatial genetic structure in Norway lobster (Nephrops norvegicus) on fishing grounds in Icelandic waters. ICES J Mar Sci 68:20-25

* Pringle JM, Blakeslee AM, Byers JE, Roman J (2011) Asymmetric dispersal allows an upstream region to control population structure throughout a species' range. Proc Natl Acad Sci USA 108:15288-15293

*Pritchard JK, Stephens M, Donnelly P (2000) Inference of population structure using multilocus genotype data. Genetics 155:945-959

*Putman AI, Carbone I (2014) Challenges in analysis and interpretation of microsatellite data for population genetic studies. Ecol Evol 4:4399-4428

R Core Team (2012) R: a language and environment for statistical computing. R Foundation for Statistical Computing, Vienna

Raymond M, Rousset F (1995) GENEPOP (version 1.2): population genetics software for exact tests and ecumenicism. J Hered 86:248-249

Reiss H, Hoarau G, Dickey-Collas M, Wolff WJ (2009) Genetic population structure of marine fish: mismatch between biological and fisheries management units. Fish Fish 10:361-395

* Ryman N, Palm S (2006) POWSIM: a computer program for assessing statistical power when testing for genetic differentiation. Mol Ecol Notes 6:600-602

* Ryman N, Palm S, André C, Carvalho GR and others (2006) Power for detecting genetic divergence: differences between statistical methods and marker loci. Mol Ecol 15:2031-2045

Schmalenbach I, Franke HD (2010) Potential impact of climate warming on the recruitment of an economically and ecologically important species, the European lobster 
(Homarus gammarus) at Helgoland, North Sea. Mar Biol 157:1127-1135

Schmalenbach I, Mehrtens F, Janke M, Buchholz F (2011) A mark-recapture study of hatchery-reared juvenile European lobsters, Homarus gammarus, released at the rocky island of Helgoland (German Bight, North Sea) from 2000 to 2009. Fish Res 108:22-30

Skerritt DJ, Robertson PA, Mill AC, Polunin NVC, Fitzsimmons C (2015) Fine-scale movement, activity patterns and home-ranges of European lobster Homarus gammarus. Mar Ecol Prog Ser 536:203-219

Teacher AGF, Griffiths DJ, Hodgson DJ, Inger R (2013) Smartphones in ecology and evolution: a guide for the app-rehensive. Ecol Evol 3:5268-5278

Triantafyllidis A, Apostolidis AP, Katsares V, Kelly E and others (2005) Mitochondrial DNA variation in the European lobster (Homarus gammarus) throughout the range. Mar Biol 146:223-235

Ulrich I, Muller J, Schutt C, Buchholz F (2001) A study of population genetics in the European lobster, Homarus gammarus (Decapoda, Nephropidae). Crustaceana 74 : 825-837

Wahle RA, Castro KM, Tully O, Cobb JS (2013) Homarus. In: Phillips B (ed) Lobsters: biology, management, aquaculture \& fisheries. John Wiley \& Sons, Hoboken, p 221-258

Waples RS (1998) Separating the wheat from the chaff: patterns of genetic differentiation in high gene flow species. J Hered 89: 438-450

Waples RS, England PR (2011) Estimating contemporary

Editorial responsibility: Steven Morgan,

Bodega Bay, California, USA effective population size on the basis of linkage disequilibrium in the face of migration. Genetics 189: 633-644

*Waples RS, Punt AE, Cope JM (2008) Integrating genetic data into management of marine resources: How can we do it better? Fish Fish 9:423-449

* Ward RD (2006) The importance of identifying spatial population structure in restocking and stock enhancement programmes. Fish Res 80:9-18

*Watson HV, McKeown NJ, Coscia I, Wootton E, Ironside JE (2016) Population genetic structure of the European lobster (Homarus gammarus) in the Irish Sea and implications for the effectiveness of the first British marine protected area. Fish Res 183:287-293

*Weir BS, Cockerham CC (1984) Estimating F-statistics for the analysis of population structure. Evolution 38: 1358-1370

WWitlock MC, McCauley DE (1999) Indirect measures of gene flow and migration: $F_{\mathrm{ST}} \neq 1 /(4 N \mathrm{Nm}+1)$. Heredity 82 : $117-125$

*Wiig JR, Moland E, Haugen TO, Olsen EM (2013) Spatially structured interactions between lobsters and lobster fishers in a coastal habitat: fine-scale behaviour and survival estimated from acoustic telemetry. Can J Fish Aquat Sci 70:1468-1476

Willette DA, Allendorf FW, Barber PH, Barshis DJ and others (2014) So, you want to use next-generation sequencing in marine systems? Insight from the Pan-Pacific Advanced Studies Institute. Bull Mar Sci 90:79-122

Submitted: March 16, 2016; Accepted: October 27, 2016

Proofs received from author(s): December 20, 2016 